\title{
Natural history of brain arteriovenous malformations: a systematic review
}

\author{
Isaac Josh Abecassis, M.D., ${ }^{1}$ David S. Xu, M.D. ${ }^{2}$ H. Hunt Batjer, M.D. ${ }^{3}$ \\ AND BERNARD R. BENDOK, M.D., M.S.C.I. ${ }^{4}$ \\ ${ }^{1}$ Department of Neurological Surgery, University of Washington, Seattle, Washington; ${ }^{2}$ Division of \\ Neurological Surgery, Barrow Neurological Institute, St. Joseph's Hospital and Medical Center, Phoenix, \\ Arizona; ${ }^{3}$ Department of Neurological Surgery, University of Texas Southwestern Medical Center, Dallas, \\ Texas; and ${ }^{4}$ Departments of Neurological Surgery, Radiology, and Otolaryngology, Feinberg School of \\ Medicine, Northwestern University, Chicago, Illinois
}

Object. The authors aimed to systematically review the literature to clarify the natural history of brain arteriovenous malformations (BAVMs).

Methods. The authors searched PubMed for one or more of the following terms: natural history, brain arteriovenous malformations, cerebral arteriovenous malformations, and risk of rupture. They included studies that reported annual rates of hemorrhage and that included either 100 patients or 5 years of treatment-free follow-up.

Results. The incidence of BAVMs is $1.12-1.42$ cases per 100,000 person-years; $38 \%-68 \%$ of new cases are first-ever hemorrhage. The overall annual rates of hemorrhage for patients with untreated BAVMs range from $2.10 \%$ to $4.12 \%$. Consistently implicated in subsequent hemorrhage are initial hemorrhagic presentation, exclusively deep venous drainage, and deep and infrantentorial brain location. The risk for rupture seems to be increased by large nidus size and concurrent arterial aneurysms, although these factors have not been studied as thoroughly. Venous stenosis has not been implicated in increased risk for rupture.

Conclusions. For patients with BAVMs, although the overall risk for hemorrhage seems to be $2.10 \%-4.12 \%$ per year, calculating an accurate risk profile for decision making involves clinical attention and accounting for specific features of the malformation.

(http://thejns.org/doi/abs/10.3171/2014.6.FOCUS14250)

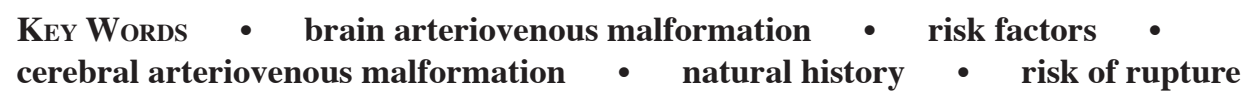

$\mathrm{F}$ IRST described by Steinheil in 1895, brain arteriovenous malformations (BAVMs) are a complex of abnormal arteries and veins that directly fistualize without an intervening capillary bed. From a purely categorical level, BAVMs differ from other fistulous vascular malformations, such as vein of Galen malformations, dural arteriovenous fistulas, or secondary malformations that arise from trauma, or neovascularization that occurs after chronic cerebral venous occlusion. Because BAVMs can differ in size, location, morphology, and angioarchitecture, clinical management varies substantially from patient to patient. The decision to proceed with treatment of a BAVM ultimately hinges on weighing the subsequent risk for intracranial hemorrhage with the immediate risks from intervention. Unfortunately, the natural history of BAVMs is still largely unknown. Current data are mostly limited to isolated single-center case series. Recently, ARUBA (A Randomized Trial of Unruptured Brain Arteriovenous Malformations) - a trial that randomly as-

Abbreviation used in this paper: $\mathrm{BAVM}=$ brain arteriovenous malformation. signed AVM patients to either a conservative medical management group or an intervention group (any sort of intervention, including surgery, embolization, or Gamma Knife) - was stopped by the National Institute of Neurological Disorders and Stroke because after a mean followup time of 33 months, the event rate (death or symptomatic stroke) was more than 3 times higher among patients in the intervention group than among those in the medical management group..$^{30}$ Thus, it is imperative that clinicians have a detailed understanding of the existing literature so that they can effectively counsel patients about the precise and individualized natural history of BAVMs. Gross and Du recently published a meta-analysis of the risk factors that predict hemorrhage in AVMs. They found that rates of future rupture were significantly increased among patients with prior hemorrhage, deep brain location, exclusive deep venous drainage, and associated aneurysms. ${ }^{12}$ Our goal in this study was to more broadly and inclusively survey the literature on this topic and to summarize reasonably powered studies of the natural history of BAVMs and the independent rates of rupture. Additionally, we review BAVM epidemiology and presenting symptoms. 


\section{J. Abecassis et al.}

\section{BAVM Definition}

McCormick first elaborated a classification system for cerebral vascular lesions that took into account the histological characteristics of the vascular supply, presence of intervening brain parenchyma, and presence of gliotic reactions within surrounding neural tissue. ${ }^{26}$ BAVMs emerged as a distinct fistulous vascular entity because of the involvement of arterial elements possessing muscular and elastic laminae and the presence of intervening gliomatous brain parenchyma. Recently, a joint review by the American Association of Neurological Surgeons, the Congress of Neurological Surgeons, and the American Academy of Neurology refined the operational definition of BAVMs to specify that they include an abnormal complex of afferent arteries communicating with draining veins that are distinct from other congenital vascular lesions such as vein of Galen malformations and dural arteriovenous malformations. ${ }^{19}$ Although BAVMs remain a distinct pathological entity, they can occur within the setting of other vascular disorders such as moyamoya disease, hereditary hemorrhagic telangiectasia syndrome, and Sturge-Weber syndrome.

\section{Epidemiology}

There are no population-based prevalence data on BAVMs. However, 6 population-based studies have examined the incidence of symptomatic and incidentally discovered BAVMs. ${ }^{1,4,5,10,15,18,34}$ It should be noted that the strict definition of incidence is the development of disease in an initially disease-free population. All of the studies to be discussed relied on patients who were primarily symptomatic at initial presentation, unquestionably missing a large number of patients with asymptomatic (silent) cases, in whom symptoms might later develop. Therefore, the semantically correct term is "rate of detection" rather than "incidence." However, we will use the latter term because it is more widely understood and has been applied in a similar fashion in the study of other diseases, such as malignancies.

The first population-based study to examine BAVM epidemiology was a retrospective review spanning 27 years, performed by Brown et al., who examined medical records from the Mayo Clinic to study cerebral vascular malformations in Olmsted County, Minnesota. ${ }^{4,5}$ From those data, the authors accumulated 48 cases of BAVMs and derived an incidence rate of 2.05 cases per 100,000 person-years (95\% CI 1.46-2.64). When cerebral vascular malformations for which hemorrhage was the presenting symptom were examined, the authors' data yielded 20 cases, 17 (85\%) of which were caused by BAVMs, which corresponds to an age- and sex-adjusted incidence of 0.82 cases per 100,000 person-years (95\% CI 0.46-1.19). Although a specific incidence rate for BAVMs with hemorrhage as the presenting symptom was not calculated, $85 \%$ of their cases in which hemorrhage was the presenting symptom were caused by BAVMs, and this figure is probably a close approximation. Jessurun et al. arrived at a similar incidence rate after an 11-year retrospective population-based review conducted in the Netherlands Antilles. ${ }^{18}$ They found 17 cases of BAVMs, 16 of which were symptomatic, yielding an incidence of 1.1 cases per 100,000 patient-years. However, the generalization of this finding is limited by the ethnic homogeneity of the study population and by the large proportion of BAVM patients who had coexisting Osler-Weber-Rendu syndrome (35\%).

More recent data from 4 multicenter populationbased studies revealed consistent statistics for BAVM incidence as well as incidence of first-ever hemorrhage. In 2001, Hillman reported a series of 135 BAVM cases diagnosed prospectively over 11 years within a medical catchment area in Sweden. ${ }^{15}$ Hillman calculated a BAVM incidence of 1.24 cases per 100,000 person-years and an incidence rate of 0.84 cases per 100,000 person-years for BAVMs with hemorrhage as the initial presenting symptom. In 2003, initial data were published from the New York Islands Arteriovenous Malformation Study, an ongoing prospective multicenter study examining the incidence and associated morbidity and mortality rates for patients with newly diagnosed BAVMs who reside on Manhattan Island, Staten Island, or Long Island. ${ }^{34}$ The data revealed 284 newly encountered BAVM patients, yielding an incidence of 1.34 cases per 100,000 person-years and an incidence rate of 0.51 cases per 100,000 person-years for BAVMs with hemorrhage at initial presentation. In a study of newly diagnosed BAVMs in Scotland from 1999 to 2000, Al-Shahi et al. found a similar incidence rate of 1.12 cases per 100,000 person-years $(95 \%$ CI 0.90 $1.37)$ and a rate of 0.51 (95\% CI $0.37-0.69)$ for first-ever BAVM hemorrhage. ${ }^{1}$ A recent study by Gabriel et al. encompassed enrollees in the Kaiser Permanente Medical Care Program of Northern California from 1995 through $2004 .^{10}$ The authors derived a BAVM incidence rate of 1.42 cases per 100,000 person-years (95\% CI $1.20-1.57$ ) and a first-ever hemorrhage incidence of 0.70 cases per $100,000$ person-years (95\% CI $0.63-0.83)$. When compared with each other, the 4 multicenter studies produced a narrow incidence range of $1.12-1.42$ cases per 100,000 person years for BAVMs; $38-68 \%$ of new cases had firstever hemorrhage at presentation.

\section{Presentation}

Across 9 of the largest single-center and populationbased series of BAVM cases, hemorrhage is consistently described as being the most common initial presenting feature of BAVMs, occurring $50 \%$ of the time at initial diagnosis (Tables 1-2).17,36 After hemorrhage, the next most common presenting feature is seizures, occurring $30 \%$ of the time, followed by headaches, which were reported to occur $5 \%-14 \%$ of the time by only 2 cases series. These data vary considerably, probably depending on their geographic origin; an initial hemorrhage rate of $71 \%$ was found for the Nordic countries of Sweden, the Netherlands, and Finland; and rates of $42 \%$ and $52 \%$ were found for North America and Western Europe. Similarly, case series reports described seizures as a presenting feature for $19 \%$ of patients in Nordic countries and North America but for $31 \%$ of patients in Western Europe and the Middle East. This variation is probably at least partially the result of geographic differences in diagnostic medical practices and institutional referral patterns. 
TABLE 1: Authors and numbers of cases for presentation data described in population-based studies arranged by geographic region

\begin{tabular}{llr}
\hline \multirow{2}{*}{ Region } & \multicolumn{1}{c}{ Authors \& Year } & $\begin{array}{r}\text { Total } \\
\text { Cases }\end{array}$ \\
\hline Nordic & Jessurun et al., 1993 & 17 \\
& Hillman et al., 2001 & 135 \\
& Ondra et al., 1990 & 160 \\
North America & Brown et al., 19964 & 26 \\
& Stapf et al., 2001 & 284 \\
& Gabriel et al., 2010 & 401 \\
Western Europe, Asia, \& Middle & Stefani et al., 2002 & 390 \\
\hline East & Al-Shahi et al., 2003 & 92 \\
total & Hofmeister et al., 2000 & 662 \\
\hline
\end{tabular}

\section{Risk for Spontaneous Hemorrhage}

The risks associated with treatment of BAVMs must be weighed against the consequences associated with their natural history, among which rupture and subsequent hemorrhagic stroke are the most devastating. Two methods for estimating the annual risk for intracranial hemorrhage have been described in the literature. The traditional method uses date of diagnosis as the start point in the time frame; another uses birth date. An epidemiological study found no statistically significant difference between the 2 rates of hemorrhage..$^{20}$ This group also found that, when comparing the 2 timeline curves, there was a 10 -year offset between them, suggesting some sort of biological change around 10 years of age that influences the natural history of BAVM and risk for intracranial hemorrhage. ${ }^{20}$

Tables 3-5 summarize the findings of the natural history studies reported in the literature that examined rates of BAVM rupture. . $, 3,13,25,27,41$ Along with each study is listed the number of patients examined by the authors and the mean treatment-free follow up period; this information enables the reader to gauge the significance of the results.
These tables also indicate risk factors that the authors examined and found-at a statistically significant level-to have no influence on risk for subsequent rupture.

Because of the heterogeneous nature of these lesions, a multitude of factors might increase the risk for rupture and hemorrhage. It is important to use multivariate modeling to differentiate between factors that independently predict risk for hemorrhage and factors that are merely associated with the true predictive feature. For example, by using a univariate model, Stefani et al. identified a number of factors associated with hemorrhage events, including arterial aneurysms, deep feeder arteries, a single draining vein, large (greater than $3 \mathrm{~cm}$ ) nidus size, and deep brain location. However, according to multivariate analysis, only nidus size and deep brain location were significant. ${ }^{37}$ Some factors might be correlated with hemorrhage at presentation but might not, in fact, be predictive of further hemorrhage. A small AVM nidus, for example, is often found alongside lesions that are hemorrhagic at presentation, but a large nidus found at follow-up seems to predict additional hemorrhage events. ${ }^{21}$ Similarly, because hemorrhage at presentation is more frequent among children with BAVMs, some groups have insisted that young age is a risk factor for subsequent hemorrhage. Stapf et al. found young age to be a risk factor according to univariate but not multivariate analysis, probably because younger age is associated with hemorrhage at initial presentation. ${ }^{35}$ But in a thorough and statistically sophisticated study involving more than 1000 BAVM patients, Fullerton et al. showed that after accounting for the increased frequency of hemorrhage at presentation in children, risk for hemorrhage was actually lower among younger patients. ${ }^{8}$ Thus, one must be aware of the potential for confounding variables in studies of BAVM natural history. Such studies can often be affected by selection bias, given that each medical center might attract different patients. For example, Pollock et al. reviewed angiographic data from 315 BAVM patients who had undergone radiosurgery at their center, and they developed a risk stratification model based on the presence of 3 risk factors: hemorrhage at initial presentation, single draining vein, and diffuse AVM morphology. ${ }^{33}$ Although the overall annual rate of hemorrhage was $2.4 \%$

TABLE 2: Common presentation features of BAVMs as described in population-based studies*

\begin{tabular}{|c|c|c|c|c|c|c|c|}
\hline \multicolumn{3}{|c|}{ Hemorrhage } & \multicolumn{3}{|c|}{ Seizures } & \multicolumn{2}{|c|}{ Headaches } \\
\hline No. of Patients & $\%$ in Study & $\%$ in Region & No. of Patients & $\%$ in Study & $\%$ in Region & No. of Patients & $\%$ in Study \\
\hline 16 & 94.1 & \multirow{3}{*}{71.8} & 2 & 11.8 & \multirow{3}{*}{19.2} & NR & \\
\hline 94 & 69.6 & & 20 & 14.8 & & NR & \\
\hline 114 & 71.3 & & 38 & 23.8 & & 8 & 5.0 \\
\hline 17 & 65.4 & \multirow{4}{*}{42.5} & 5 & 19.2 & \multirow{4}{*}{19.2} & NR & \\
\hline 108 & 38.0 & & & & & NR & \\
\hline 197 & 49.1 & & & & & NR & \\
\hline 146 & 37.4 & & & & & NR & \\
\hline 42 & 45.7 & \multirow{2}{*}{51.7} & 25 & 27.2 & \multirow{2}{*}{34.6} & NR & \\
\hline \multirow[t]{2}{*}{348} & 52.6 & & 236 & 35.6 & & 96 & 14.5 \\
\hline & 49.9 & & & 29.9 & & & 9.8 \\
\hline
\end{tabular}

${ }^{*} \mathrm{NR}=$ not reported; blank cells indicate not applicable. 


\section{J. Abecassis et al.}

TABLE 3: Data from hemorrhage risk factor studies, by author*

\begin{tabular}{|c|c|c|c|c|}
\hline Authors \& Year & $\begin{array}{l}\text { No. of Patients } \\
\text { Followed }\end{array}$ & $\begin{array}{l}\text { Mean Treatment-Free } \\
\text { Follow-Up Time (yrs) }\end{array}$ & Risk Factors Implicated in Study & $\begin{array}{l}\text { Cumulative Risk for } \\
\text { Hemorrhage (\%/yr) }\end{array}$ \\
\hline Graf et al., 1983 & 191 & 3.6 & HIP, nidus size $<3 \mathrm{~cm}$ & 1.95 \\
\hline Fults \& Kelly, 1984 & 83 & 8.7 & HIP & 4.12 \\
\hline Crawford et al., 1986 & 217 & 10.4 & HIP, age & 2.1 (0.8 w/o RF) \\
\hline Brown et al., 1988 & 166 & 8.2 & none & 2.2 \\
\hline Ondra et al., 1990 & 160 & 23.7 & none & 4 \\
\hline Mast et al., 1997 & 281 & 0.85 & HIP, DVD, sex & 8.8 (2.2 w/o RF) \\
\hline Hirai et al., 1998 & 24 & 9.3 & $\begin{array}{l}\text { nidus size }>6 \mathrm{~cm} \text {, DVD, venous ste- } \\
\text { nosis, nidal aneurysm }\end{array}$ & 3.6 \\
\hline Mine et al., 2000 & 55 & 10.5 & nidus size $>6 \mathrm{~cm}$ & 2.3 \\
\hline Stefani et al., 2002 & 390 & 3.1 & nidus size $>3 \mathrm{~cm} \mathrm{DBL}$ & 3.2 \\
\hline ApSimon et al., 2002 & 240 & 10.11 & age & 0.78 \\
\hline Halim et al., 2004 & 790 & 3.99 & HIP & 2.1 (1.5 w/o RF) \\
\hline Stapf et al., 2006 & 622 & 2.27 & HIP, DBL, DVD & 2.8 (0.9 w/o RF) \\
\hline Yamada et al., 2007 & 305 & 2.93 & $\begin{array}{l}\text { HIP, headache at pres, asymptom- } \\
\text { atic at pres, DBL, age }<20 \text { yrs, } \\
\text { and female if w/ HIP }\end{array}$ & 4.7 (3.12 w/o RF) \\
\hline Hernesniemi et al., 2008 & 238 & 13.5 & $\begin{array}{l}\text { HIP, DBL, nidus size }>5 \mathrm{~cm} \text {, infra- } \\
\text { tentorial (DVD according to uni- } \\
\text { variate analysis) }\end{array}$ & 2.4 \\
\hline da Costa et., 2009 & 678 & 2.85 & $\begin{array}{l}\text { HIP (associated aneurysm \& DVD ac- } \\
\text { cording to univariate analysis) }\end{array}$ & 4.41 \\
\hline
\end{tabular}

* $\mathrm{DBL}=$ deep and infrantentorial brain location; $\mathrm{DVD}=$ deep vein drainage; HIP = hemorrhage at initial presentation; pres = presentation; RF = risk factor. Boldface indicates validation in a multivariate statistical analysis model; italics indicate implication in the study but conditionally (in this case only if there was simultaneous hemorrhage at initial presentation).

TABLE 4: Selected risk factors and rates of hemorrhage from natural history studies*

\begin{tabular}{|c|c|c|c|c|c|}
\hline \multicolumn{6}{|c|}{ Risk Factors \& Associated Annual Risk for Hemorrhage in \%/yr (positive or negative compared w/ cumulative risk) } \\
\hline HIP & $\begin{array}{l}\text { Seizure at } \\
\text { Presentation }\end{array}$ & $\begin{array}{l}\text { Headaches at } \\
\text { Presentation }\end{array}$ & $\begin{array}{l}\text { Asymptomatic at } \\
\text { Presentation }\end{array}$ & Nidus Size & Patient Age \\
\hline $2.35(+)$ & NS & NS & NS & $10.4(+)$ & NS \\
\hline $4.49(+)$ & $1.79(-)$ & NS & NS & NA & NA \\
\hline $2.55(+)$ & $1.05(-)$ & NS & NS & NA & $9.89(+)$ if $>60 \mathrm{yrs}$ \\
\hline NS & NA & NS & NS & NA & NS \\
\hline NA & NS & NS & NS & NS & NS \\
\hline $17.8(+)$ & NA & NS & NS & NA & NA \\
\hline NS & NS & NS & NS & $5.4(+)$ if nidus $>6 \mathrm{~cm}$ & NS \\
\hline NA & NS & NS & NS & $6.4(+)$ & NA \\
\hline NA & NS & NS & NS & $\begin{array}{l}\text { odds ratio of } 2.5(+) \text { if nidus } \\
>3 \mathrm{~cm}\end{array}$ & NS \\
\hline NS & NS & NS & NS & NS & $(+)$ age \& risk not specified \\
\hline $2.8(+)$ & NS & NS & NS & NA & NA \\
\hline $4.5(+)$ & NS & NS & NS & NS & NS \\
\hline $6.84(+)$ & $2.2(-)$ & $6.48(+)$ & $6.44(+)$ & NA & $\begin{array}{l}(+) 20.28 \text { if }<20 \text { yrs w/ HIP vs } 5.28 \text { if } \\
>20 \text { yrs }\end{array}$ \\
\hline $2.8(+)$ & NS & NS & NS & $3.5(+)$ if nidus $>5 \mathrm{~cm}$ & NS \\
\hline $7.48(+)$ & $4.16(-)$ & NS & NS & NS & NS \\
\hline
\end{tabular}

* NA = studied but not associated; NS = not studied; + = positive; - = negative. 
Natural history of BAVMs

TABLE 5: Selected risk factors and rates of hemorrhage from natural history studies*

\begin{tabular}{|c|c|c|c|c|}
\hline \multicolumn{5}{|c|}{ Risk Factors \& Associated Annual Risk for Hemorrhage in \%/yr (positive or negative compared w/ cumulative risk) } \\
\hline DBL & Patient Sex & DVD & $\begin{array}{l}\text { Venous } \\
\text { Stenosis }\end{array}$ & $\begin{array}{l}\text { Concurrent } \\
\text { Aneurysm }\end{array}$ \\
\hline NS & NS & NS & NS & NS \\
\hline NS & NS & NS & NS & NS \\
\hline NA & NA & NS & NS & NS \\
\hline NS & NS & NS & NS & NS \\
\hline NS & NS & NS & NS & NS \\
\hline NS & male $(+)$ hazard ratio $=9.2$ & $(+)$ hazard ratio $=4.9$ & NS & NS \\
\hline NS & NS & $8.6(+)$ & $5.5(+)$ & $8.5(+)$ \\
\hline $7.5(+)$ & NA & NS & NS & NS \\
\hline odds ratio of $5.56(+)$ & NS & NA & NS & NS \\
\hline NS & NS & NS & NS & NS \\
\hline NS & NA & NA & NS & NS \\
\hline $3.1(+)$ infratentorial = none & NS & $2.4(+)$ & NS & NS \\
\hline (+) if w/ HIP hazard ratio of 3.07 & female w/ HIP (+) hazard ratio of 2.59 & NA & NS & NS \\
\hline $4.1(+)$ infratentorial $=6.7(+) \dagger$ & NS & $3.4(+)$ & NS & NS \\
\hline NA & NA & $5.42(+)$ & NS & $6.93(+)$ \\
\hline
\end{tabular}

* NA = studied but not associated; NS = not studied.

$\dagger$ Infratentorial lesions examined separately.

per year, which is similar to that reported by most natural history studies, the risk factor analysis cannot really be applied to BAVMs in general, given that $87 \%$ of lesions were small and $31 \%$ were deeply located. Nonetheless, this finding does shed some light on the natural history of small BAVMs that are potential candidates for radiosurgery.

Since the 1980s, multiple population-based studies have estimated the overall risk for hemorrhage to range from $0.78 \%$ to $34.3 \%$ cases per year. In addition, these studies have attempted to stratify patients according to specific BAVM characteristics predictive of rupture. The most common feature investigated was hemorrhage at initial presentation, although exclusively deep venous drainage and deep and infrantentorial brain location are also consistently implicated in subsequent hemorrhage.

\section{Overall Rates of Future Hemorrhage Among Patients With Hemorrhage at Initial Presentation}

By studying a relatively large patient population, Fults and Kelly first documented the observation that BAVM lesions with hemorrhage at initial presentation were more likely to subsequently rerupture. ${ }^{9}$ They calculated a $4.12 \%$ annual risk for future hemorrhage in the overall population (composed predominantly of patients with hemorrhage at initial presentation), a slight increase among those patients with hemorrhage at initial presentation (4.49\%), and a markedly lower rate $(1.79 \%)$ among patients with a history of seizure at initial presentation. In addition to noting a particularly poor prognosis for patients with lesions in the posterior fossa, the authors observed that although the risk for future hemorrhage for BAVMs with hemorrhage at initial presentation was markedly elevated in the first year after hemorrhage $(17.9 \%)$, the rate decreased to $3 \%$ per year after 5 years and then to $2 \%$ per year after 10 years (Tables 6-9). One year earlier (1983), Graf et al. observed similar findings in their retrospective review of 191 BAVM patients from Iowa. ${ }^{11}$ Specifically, they noted that the risk for hemorrhage decreased back to near baseline levels after 1 year. For a larger cohort of 217 patients at the University of Liverpool, Crawford et al. also documented increased rates of hemorrhage among patients with hemorrhage at initial presentation, although the rates were

TABLE 6: Authors and studies that examined BAVM natural history rupture rates with multiple time points, risk factors analyzed

\begin{tabular}{|c|c|c|c|}
\hline Authors \& Year & $\begin{array}{c}\text { No. of } \\
\text { Patients }\end{array}$ & $\begin{array}{c}\text { Mean } \\
\text { Treatment-Free } \\
\text { Follow-Up } \\
\text { Period (yrs) }\end{array}$ & Risk Factors \\
\hline Graf et al., 1983 & 191 & 3.96 & $\begin{array}{l}\text { HIP, small nidus size } \\
(<3 \mathrm{~cm})\end{array}$ \\
\hline Mast et al., 1997 & 281 & 0.85 & HIP, DVD, male \\
\hline Halim et al., 2004 & 790 & 3.99 & HIP \\
\hline $\begin{array}{l}\text { Yamada et al., } \\
2007\end{array}$ & 305 & 2.93 & $\begin{array}{l}\text { HIP, DBL + HIP, female } \\
\quad+\text { HIP, young age } \\
\quad+\text { HIP }\end{array}$ \\
\hline $\begin{array}{l}\text { Hernesniemi et } \\
\text { al., } 2008\end{array}$ & 238 & 13.5 & $\begin{array}{l}\text { HIP, DBL, nidus size } \\
\quad>5 \mathrm{~cm} \text {, infratentorial } \\
\text { (DVD only on univar- } \\
\text { iate analysis) }\end{array}$ \\
\hline $\begin{array}{r}\text { da Costa et } \\
\text { al., } 2009\end{array}$ & 678 & 2.85 & $\begin{array}{l}\text { HIP, associated aneu- } \\
\text { rysms, DVD }\end{array}$ \\
\hline
\end{tabular}


TABLE 7: Cumulative risks for rupture, and selected risk factors with rates of hemorrhage for natural history studies with multiple time points

\begin{tabular}{|c|c|c|c|c|}
\hline \multirow[b]{2}{*}{ Time Point } & \multirow[b]{2}{*}{ Cumulative Risk for Hemorrhage (\%/yr) } & \multicolumn{3}{|c|}{$\begin{array}{l}\text { Risk Factors \& Associated Annual Risk for Hemorrhage in \%/yr } \\
\text { (positive or negative compared w/ cumulative risk) }\end{array}$} \\
\hline & & HIP & Seizure History at Presentation & Nidus Size \\
\hline $1 \mathrm{yr}$ & 2 & $6(+)$ & & $10(+)$ \\
\hline $5 \mathrm{yrs}$ & 2.8 & $2.6(-)$ & & $10.4(+)$ \\
\hline $10 \mathrm{yrs}$ & 3.1 & $1.6(-)$ & & \\
\hline $20 \mathrm{yrs}$ & 1.95 & $2.35(+)$ & & \\
\hline $1 \mathrm{yr}$ & 0 & $32.9(+)$ & & \\
\hline$\geq 2 \mathrm{yrs}$ & 2.9 & $11.3(+)$ & & \\
\hline overall & 2.1 & & & \\
\hline $1 \mathrm{mo}$ & 4 & $9(+)$ & & \\
\hline $3 \mathrm{mos}$ & 2 & $5(+)$ & & \\
\hline $6 \mathrm{mos}$ & 1 & $3(+)$ & & \\
\hline $1 \mathrm{yr}$ & 1 & $2(-)$ & & \\
\hline $2 \mathrm{yrs}$ & 1 & $2(-)$ & & \\
\hline $5 \mathrm{yrs}$ & 0.5 & $1(-)$ & & \\
\hline $10 \mathrm{yrs}$ & 0.3 & $0.7(-)$ & & \\
\hline overall & 4.7 (3.12 w/no RF) & $6.84(+)$ & & \\
\hline $1 \mathrm{yr}$ & & $15.42(+)$ & $2.2(-)$ & \\
\hline $2-5 \mathrm{yrs}$ & & $5.32(+)$ & & \\
\hline$>5 \mathrm{yrs}$ & & $1.72(-)$ & & \\
\hline overall & 2.4 & $2.8(+)$ & & $3.5(+)$ \\
\hline $1-5 \mathrm{yrs}$ & 4.7 & $6.2(+)$ & & $5.5(+)$ \\
\hline$>5 \mathrm{yrs}$ & 1.6 & $1.7(+)$ & & $2.7(+)$ \\
\hline overall & 4.41 & $7.48(+)$ & & \\
\hline $1 \mathrm{yr}$ & 4.8 & $9.65(+)$ & 4.16 & \\
\hline $2-5 \mathrm{yrs}$ & 3.95 & $6.3(+)$ & & \\
\hline$>5 \mathrm{yrs}$ & 3.9 & $3.67(-)$ & & \\
\hline
\end{tabular}

lower $(2.10 \%$ overall, $2.55 \%$ with hemorrhage at initial presentation, and $1.05 \%$ with seizures). ${ }^{6}$ In 1988, Brown et al. found a $2.2 \%$ overall annual rate of hemorrhage for a cohort of patients in the United States. ${ }^{3}$ Despite exploring a variety of factors including size, shunt resistance, seizures, and hypertension, the authors found no features to be predictive of hemorrhage. Mast et al. also documented a 2.2\% annual hemorrhage rate for their cohort and an unusually high increase in risk for hemorrhage among patients with hemorrhage at initial presentation (17.8\%), although their mean follow-up period was extraordinarily short (8.5 and 11.9 months for patients with and without hemorrhage at initial presentation). ${ }^{25}$ ApSimon et al. documented a markedly low annual rate of hemorrhage $(0.78 \%)$, although this group used an atypical analytical method (nonstatistical regression) and definitively treated a large proportion of their patients, possibly masking the true overall rate that would occur in natural history. ${ }^{2}$

In 1990, Ondra et al. examined health records for BAVM patients in Finland, where national medical records for a relatively stable and homogeneous population were conveniently accessible. After following 160 patients for a mean of 23.7 years, the authors found no difference in the clinical course-including rates of death, subsequent hemorrhage, and morbidity-of previously ruptured and unruptured lesions. Specifically, they documented a $4.0 \%$ annual rate of rupture, regardless of presentation. ${ }^{32}$ Hernesniemi et al. recently reevaluated this same cohort in Finland with the addition of new patients for a mean follow-up period of 13.5 years. After using sophisticated statistical models, including a Kaplan-Meier life table analysis and Cox multivariate modeling, the authors found the annual hemorrhage rate to be $2.4 \%$, noting that the rate was highest in the first 5 years after diagnosis (4.7\%) and lower after those first 5 years $(1.6 \%) .^{14}$ This rate was significantly lower than that reported by Ondra et al. because Hernesniemi et al. followed patients only until their first hemorrhage event, whereas Ondra's group continued to follow and include patients with multiple hemorrhage events. Furthermore, whereas Ondra et al. found no difference in rupture rates for patients with different presentations, Hernesniemi's group noted that among patients with previously ruptured BAVMs, the annual hemorrhage rate was $6.2 \%$ during the first 5 years and only $2.3 \%$ among those with nonruptured lesions. Using univariate and multivariate analyses, Stefani et al. failed to identify 


\section{Natural history of BAVMs}

TABLE 8: Selected risk factors with rates of hemorrhage for natural history studies with multiple time points

\begin{tabular}{|c|c|c|c|c|c|c|c|}
\hline \multirow[b]{2}{*}{ Time Point } & \multirow[b]{2}{*}{$\begin{array}{l}\text { Cumulative Risk for Hemorrhage } \\
(\% / y r)\end{array}$} & \multicolumn{5}{|c|}{$\begin{array}{l}\text { Risk Factors \& Associated Annual Risk for Hemorrhage in \%/yr } \\
\text { (positive or negative compared w/ cumulative risk) }\end{array}$} & \multirow[b]{2}{*}{$\begin{array}{l}\text { Neurologica } \\
\text { Deficit }\end{array}$} \\
\hline & & $\mathrm{DBL}$ & Infratentorial Location & DVD & $\mathrm{DBL}+\mathrm{HIP}$ & $\begin{array}{l}\text { Associated } \\
\text { Aneurysm }\end{array}$ & \\
\hline $1 \mathrm{yr}$ & 2 & & & & & & \\
\hline $5 \mathrm{yrs}$ & 2.8 & & & & & & \\
\hline $10 \mathrm{yrs}$ & 3.1 & & & & & & \\
\hline $20 \mathrm{yrs}$ & 1.95 & & & & & & \\
\hline $1 \mathrm{yr}$ & 0 & & & 101 & & & \\
\hline$\geq 2 \mathrm{yrs}$ & 2.9 & & & $4.9(+)$ & & & \\
\hline overall & 2.1 & & & & & & \\
\hline $1 \mathrm{mo}$ & 4 & & & & & & \\
\hline $3 \mathrm{mos}$ & 2 & & & & & & \\
\hline $6 \mathrm{mos}$ & 1 & & & & & & \\
\hline $1 \mathrm{yr}$ & 1 & & & & & & \\
\hline $2 \mathrm{yrs}$ & 1 & & & & & & \\
\hline $5 \mathrm{yrs}$ & 0.5 & & & & & & \\
\hline $10 \mathrm{yrs}$ & 0.3 & & & & & & \\
\hline overall & 4.7 (3.12 w/ no RF) & & & & & & $1.73(-)$ \\
\hline $1 \mathrm{yr}$ & & & & & $11.41(+)$ & & \\
\hline \multicolumn{8}{|l|}{$2-5 \mathrm{yrs}$} \\
\hline \multicolumn{8}{|l|}{$>5 \mathrm{yrs}$} \\
\hline overall & 2.4 & $4.1(+)$ & $6.7(+)$ & $3.4(+)$ & & & \\
\hline $1-5 \mathrm{yrs}$ & 4.7 & $8.9(+)$ & $11.6(+)$ & $8.1(+)$ & & & \\
\hline$>5 \mathrm{yrs}$ & 1.6 & $2.2(+)$ & $3.6(+)$ & 1.6 & & & \\
\hline overall & 4.41 & & & $5.42(+)$ & & $6.93(+)$ & \\
\hline $1 \mathrm{yr}$ & 4.8 & & & $6.87(+)$ & & $9.35(+)$ & \\
\hline $2-5 y r s$ & 3.95 & & & $4.6(+)$ & & $5.41(+)$ & \\
\hline$>5$ yrs & 3.9 & & & $4.22(+)$ & & $6.01(+)$ & \\
\hline
\end{tabular}

hemorrhage at initial presentation as a risk factor for hemorrhage, but $79 \%$ of the patients in this cohort received treatment at some point. ${ }^{37}$

The overall annual rate of hemorrhage for patients with nontreated BAVMs seems to be somewhere in the range of $2.10 \%-4.12 \%$. However, factors that create reproducible trends in bleeding rates (like hemorrhage at initial presentation) are likely. In their respective data sets, multiple groups have documented significantly higher rates of hemorrhage among BAVM patients with hemorrhage at initial presentation, ranging from $1.7 \%$ to $17.8 \%$. Timeline studies reveal that the actual rate is highest in the 1st year of diagnosis $(9.65 \%-15.42 \%)$, lower in Years $2-5(5.32 \%-6.3 \%)$, and lowest after 5 years $(1.7 \%-3.67 \%)$. Halim et al. observed this decreased risk within the first year of presentation. ${ }^{13}$

\section{Deep Venous Drainage}

Several multivariate analyses have determined deep vein drainage to independently predict hemorrhage. Marks et al. performed a detailed analysis of the vascular architecture in BAVM patients and found that deep vein drainage plays a role in subsequent hemorrhage. ${ }^{24}$ Brown et al. observed no relationship between deep vein drainage and risk for hemorrhage, but the cohort they studied contained only 14 patients with just deep vein drainage. ${ }^{3}$ In 1997, Mast et al. noticed an increased rate according to multivariate analysis, ${ }^{25}$ but it was not until 2006 that Stapf et al. quantified an annual rate of hemorrhage and established deep vein drainage as 1 of the 3 major risk factors..$^{35}$ More importantly, perhaps, Stapf et al. showed that the annual risk for hemorrhage increases marginally for patients with just deep vein drainage (from $0.9 \%$ to $2.4 \%$ ); there is a tremendous interplay between deep vein drainage, deep and infrantentorial brain location, and hemorrhage at initial presentation. Accordingly, the annual risk is increased by deep vein drainage with deep and infrantentorial brain location or hemorrhage at initial presentation by $8.0 \%$ or $11.4 \%$ per year, respectively. For elucidation of the true annual rate of rupture for lesions with deep vein drainage alone and deep vein drainage in combination with other putative risk factors, more data are needed.

Over time, as risk factors, deep vein drainage has not been studied as much as hemorrhage at initial presentation, but the limited data suggest that although the risk 
TABLE 9: Selected risk factors with rates of hemorrhage for natural history studies with multiple time points

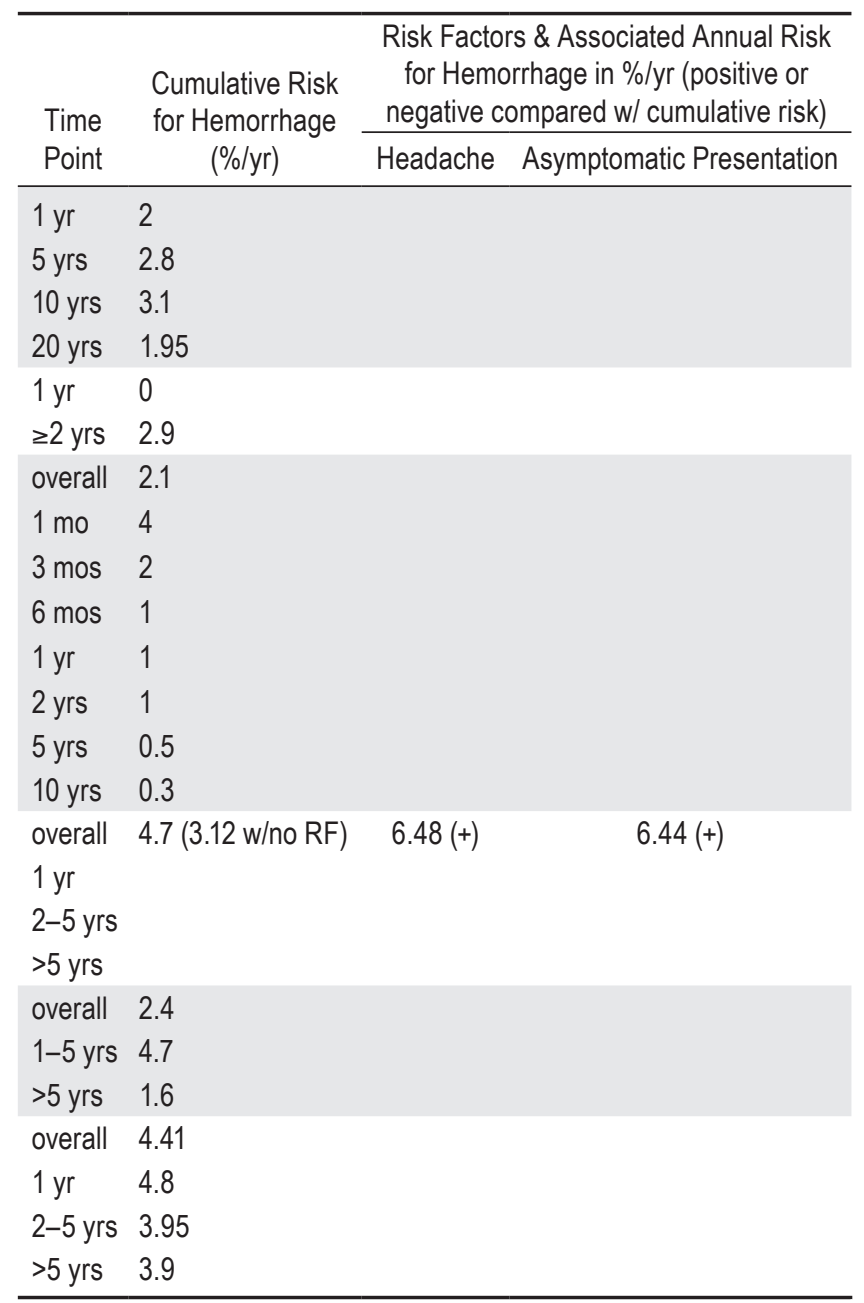

for hemorrhage does decrease slightly over time, it does not approach baseline risk values found for hemorrhage at initial presentation, at least not within 5 years. ${ }^{7}$ In other words, whatever the mechanism is behind the diminishing risk over time with hemorrhage at initial presentation (e.g., angiomatous change, vascular remodeling, fibrosis), it seems to not affect the risk conferred by deep venous vasculature.

\section{Deep Brain or Infratentorial Location}

Stapf et al. also implicated deep and infrantentorial brain location as 1 of 3 major risk factors involved in subsequent hemorrhage events. ${ }^{35}$ Many authors have observed that, similar to deep vein drainage, lesions located deeply (basal ganglia, internal capsule, thalamus, or corpus callosum) or infratentorially (brainstem or cerebellar) increase the risk for hemorrhage. Crawford et al. did not find deep and infrantentorial brain location to predict future hemorrhage and, of note, found rates of hemorrhage to be higher for lesions in the temporal lobe. ${ }^{6}$ However, patients with lesions in a deep and infrantentorial brain location comprised only $7 \%$ of the studied population. Mine et al. ob- served a significantly higher rate of rupture among deep and infratentorial brain lesions ( $7.5 \%$ vs $2.3 \%$ overall), but this finding resulted from univariate analysis only. ${ }^{27} \mathrm{To}$ our knowledge, Stapf et al. were the first to use sophisticated statistics to establish deep and infrantentorial brain location as an independent risk factor for hemorrhage, showing that-similar to deep vein drainage-a marginal increase was associated with deep and infrantentorial brain location alone $(0.9 \%-3.1 \%)$, and a much more pronounced and severe risk was associated with deep and infrantentorial brain location and deep vein drainage $8.0 \%$ per year), hemorrhage at initial presentation (14.8\% per year), or both (34.3\% per year). ${ }^{35}$ Although by using multivariate analysis Stefani et al. found a more drastic effect of deep and infrantentorial brain location alone on the risk for hemorrhage (OR 5.56), only $21 \%$ of the patients in the study remained untreated, and thus the true natural history might have been altered. ${ }^{37}$ Again, more emphasis on observing the risk for hemorrhage associated with deep and infrantentorial brain location of BAVMs, independently and over time, is needed.

\section{Venous Drainage System}

Although many groups have postulated that the venous drainage system is associated with hemorrhage, multivariate analyses have failed to establish an association between venous abnormalities (including venous stenosis, occlusion, ectasia, or obstruction) and increased risk for hemorrhage. ${ }^{22,24,38}$ After it was observed that venous bleeding was responsible for some of the hemorrhage events in BAVMs because of high-pressure shunting, venous stenosis-as well as other venous congestion issues-surfaced as a potential risk factor for hemorrhage. ${ }^{31}$ In 1985, Viñuela et al. published a retrospective series of 53 deep-seated BAVMs and provided full angiographic analyses of the lesions with a particular focus toward morphological changes in the venous walls. ${ }^{39}$ After identifying venous stenosis and/or occlusion in a large subset of the patients, the authors postulated that these changes might by responsible for increased hemorrhage at initial presentation (41/53 patients had hemorrhage at initial presentation). ${ }^{39}$ It was not until 1992 that Miyasaka et al. followed a large number of patients $(n=108)$ and for the first time used statistical analyses to determine the influence of the venous drainage system on the rate of hemorrhage. ${ }^{28}$ The patients all had supratentorial lesions, and most $(\mathrm{n}=$ 71) had hemorrhage at initial presentation. The authors found a statistically significantly higher rate of hemorrhage among lesions with fewer draining veins, impaired venous drainage (including severe stenosis [ $>50 \%]$, or occlusion of draining veins), and with deep vein drainage, although they did not perform multivariate analyses or calculate annual rates of hemorrhage. Hirai et al. followed a small number of patients $(n=24)$ in Japan for 9.3 years on average, providing the first long-term retrospective analysis of various angioarchitectural features and subsequent risk for hemorrhage. ${ }^{16}$ Although the authors did find higher annual rates of rupture among patients with venous stenosis and a concurrent intranidal aneurysm, there were only 2 patients in each category. In addition, there is no multivariate analysis or discussion regarding any major 
putative coinciding risk factors among patients, such as hemorrhage at initial presentation (half of the patients with venous stenosis and half with intranidal aneurysms also had hemorrhage at initial presentation). Nataf et al. retrospectively reviewed neuroangiographic findings for 160 BAVMs, focusing on 30 angiographic features that might play a role in predicting hemorrhage..$^{29}$ Using logistic regression, the authors developed a statistical model to predict hemorrhage and determined that deep vein drainage, venous stenosis, and venous reflux each independently increases the risk for hemorrhage. ${ }^{29}$ In 1988, Willinsky et al. found an association between venous stenosis and hemorrhage at initial presentation only for women 20-30 years of age. ${ }^{40}$ Recently, Mansmann et al. reviewed angiographic data from a much larger patient cohort (662) in a cross-sectional analysis and demonstrated that venous stenosis was associated with an increased rate of hemorrhage at initial presentation. ${ }^{23}$ Again, this finding has no implications for the risk for subsequent hemorrhage in a BAVM with venous stenosis. ${ }^{23}$ Thus, to our knowledge, no long-term prospective study with sufficient BAVM patient numbers and use of multivariate statistical analyses has been conducted to assess the true role that venous stenosis plays in rates of subsequent hemorrhage. Moreover, studies evaluating the association between venous stenosis and hemorrhage at initial presentation have been mixed; some authors found an association and others did not.

\section{Nidus Size: Small Size Associated With Hemorrhage and Large Size Predictive of Future Hemorrhage}

As discussed above, long-term studies have indicated that a small BAVM nidus (diameter generally $\leq 3 \mathrm{~cm}$ ) has been associated with hemorrhage at initial presentation, but larger lesions (diameter $>5 \mathrm{~cm}$ ) seem to predict future hemorrhage events. In 1983, Graf et al. ${ }^{11}$ observed a much higher rate of hemorrhage in small rather than in large lesions (10\% vs $2 \%$ ). However, only 12 of 71 patients in the cohort had small lesions, and $37 \%$ had a nidus of unknown size. Most studies that followed patients from 1980 to almost 2000 failed to identify nidus size as a risk factor at all, although part (if not all) of the follow-up period for these studies was before the era of CT. Although Brown et al. ${ }^{4}$ found no statistically significant relationship between nidus size and hemorrhage, they did find that rates of hemorrhage were higher for medium and large lesions. In 1998, Hirai et al. ${ }^{16}$ retrospectively reviewed 24 BAVM patients and found (albeit in a small cohort) annual bleeding rates of $5.4 \%$ for large lesions, $2.1 \%$ for small lesions, and $3.6 \%$ overall. This observation contrasted sharply with the association of small lesions with hemorrhage at initial presentation and the assumption that this association implied causation. Mine et al. (from the same institution in Japan) updated this natural history 2 years later with additional data, although the study was still small (only 55 patients). Mine et al. ${ }^{27}$ showed that the annual bleeding rate for large lesions was $6.4 \%$ and for small and medium lesions was $2.3 \%$ (these rates held through 5 years). After 20 years, the risk dropped to $3.9 \%$ for large lesions and $1.6 \%$ for small and medium lesions. Stefani et al. ${ }^{37}$ studied a much larger cohort of patients (390) and documented an odds ratio of 2.5 for lesions larger than $3 \mathrm{~cm}$ (medium and large). And in 2008, Hernesniemi et al. ${ }^{14}$ found large AVM size to independently predict future hemorrhage; the annual rates of hemorrhage were $5.5 \%$ versus $4.7 \%$ in years $1-5$ and $2.7 \%$ versus $1.6 \%$ in more than 5 years. The authors used 3 different multivariate models to test which risk factors were significantly and independently predictive of hemorrhage (and at which time points). In the first model, large nidus size was validated as a risk factor when looking at the overall study. In the second model, in addition to being significant in the overall follow-up period, size was the only significant risk factor in analysis of the first 5 years after diagnosis. In the third model, size was significant when the overall period was considered.

For large lesions, the annual risk for hemorrhage is $2.7 \%-6.4 \%$, and this rate is probably higher within the first 5 years of diagnosis. Despite numerous studies establishing a clear association between small nidus size and hemorrhage at initial presentation, it seems that large lesions are more prone to hemorrhage in subsequent years. This finding might be explained by the fact that patients with small lesions are not likely to have seizures or focal deficits or other manifestations of mass effect because small lesions often do not physically perturb nearby cortex. Instead, small lesions likely remain asymptomatic until a bleeding event. Thus, a large number of asymptomatic small BAVMs are probably not accounted for in these natural history studies. To the contrary, patients with large lesions are more likely to be symptomatic at presentation even in the absence of intracranial hemorrhage, because the mass effect can have other manifestations. From the Hernesniemi et al. ${ }^{14}$ data, one can conclude that although the risk for hemorrhage is higher within the first 5 years of diagnosis, so too is the risk for small- and medium-sized lesions. That is to say, although the risk for hemorrhage is lower after 5 years for large lesions, it seems that the risk for bleeding occurs during this later period. This concept is consistent with multivariate analysis results of Hernesniemi et al. and detection of significance only in the overall period, not in the early years.

\section{Conclusions}

Although the overall risk for hemorrhage for BAVMs does seem to be $2.10 \%-4.12 \%$ per year, calculating an accurate risk profile for decision making involves clinical attention and accounting for specific features of the malformation. Namely, rates of future hemorrhage seem to be highest for lesions with hemorrhage at initial presentation, although this risk decreases over time. Multivariate models have validated that that deep vein drainage and deep and infrantentorial brain location also are predictive of increased risk for hemorrhage, and synergistically so. A large nidus is more predictive of increased risk for future hemorrhage than is a small nidus. More information is needed to clearly delineate the role of complex venous angioarchitectural features and their precise role in the natural history of BAVMs.

\section{Disclosure}

The authors report no conflict of interest concerning the mate- 


\section{J. Abecassis et al.}

rials or methods used in this study or the findings specified in this paper.

Author contributions to the study and manuscript preparation include the following. Conception and design: Bendok, Abecassis, Batjer. Acquisition of data: Abecassis, Xu. Analysis and interpretation of data: Abecassis, Xu. Drafting the article: Bendok, Abecassis, $\mathrm{Xu}$. Critically revising the article: Bendok, Abecassis, Batjer. Reviewed submitted version of manuscript: Abecassis, Batjer. Administrative/technical/material support: Abecassis. Study supervision: Bendok, Batjer.

\section{References}

1. Al-Shahi R, Bhattacharya JJ, Currie DG, Papanastassiou V, Ritchie V, Roberts RC, et al: Prospective, population-based detection of intracranial vascular malformations in adults: the Scottish Intracranial Vascular Malformation Study (SIVMS). Stroke 34:1163-1169, 2003

2. ApSimon HT, Reef H, Phadke RV, Popovic EA: A populationbased study of brain arteriovenous malformation: long-term treatment outcomes. Stroke 33:2794-2800, 2002

3. Brown RD Jr, Wiebers DO, Forbes G, O'Fallon WM, Piepgras DG, Marsh WR, et al: The natural history of unruptured intracranial arteriovenous malformations. J Neurosurg 68:352357, 1988

4. Brown RD Jr, Wiebers DO, Torner JC, O'Fallon WM: Frequency of intracranial hemorrhage as a presenting symptom and subtype analysis: a population-based study of intracranial vascular malformations in Olmsted Country, Minnesota. J Neurosurg 85:29-32, 1996

5. Brown RD Jr, Wiebers DO, Torner JC, O'Fallon WM: Incidence and prevalence of intracranial vascular malformations in Olmsted County, Minnesota, 1965 to 1992 . Neurology 46: 949-952, 1996

6. Crawford PM, West CR, Chadwick DW, Shaw MD: Arteriovenous malformations of the brain: natural history in unoperated patients. J Neurol Neurosurg Psychiatry 49:1-10, 1986

7. da Costa L, Wallace MC, Ter Brugge KG, O'Kelly C, Willinsky RA, Tymianski M: The natural history and predictive features of hemorrhage from brain arteriovenous malformations. Stroke 40:100-105, 2009

8. Fullerton HJ, Achrol AS, Johnston SC, McCulloch CE, Higashida RT, Lawton MT, et al: Long-term hemorrhage risk in children versus adults with brain arteriovenous malformations. Stroke 36:2099-2104, 2005

9. Fults D, Kelly DL Jr: Natural history of arteriovenous malformations of the brain: a clinical study. Neurosurgery 15:658662,1984

10. Gabriel RA, Kim H, Sidney S, McCulloch CE, Singh V, Johnston $\mathrm{SC}$, et al: Ten-year detection rate of brain arteriovenous malformations in a large, multiethnic, defined population. Stroke 41:21-26, 2010

11. Graf CJ, Perret GE, Torner JC: Bleeding from cerebral arteriovenous malformations as part of their natural history. J Neurosurg 58:331-337, 1983

12. Gross BA, Du R: Natural history of cerebral arteriovenous malformations: a meta-analysis. Clinical article. J Neurosurg 118:437-443, 2013

13. Halim AX, Johnston SC, Singh V, McCulloch CE, Bennett JP, Achrol AS, et al: Longitudinal risk of intracranial hemorrhage in patients with arteriovenous malformation of the brain within a defined population. Stroke 35:1697-1702, 2004

14. Hernesniemi JA, Dashti R, Juvela S, Väärt K, Niemelä M, Laakso A: Natural history of brain arteriovenous malformations: a long-term follow-up study of risk of hemorrhage in 238 patients. Neurosurgery 63:823-831, 2008

15. Hillman J: Population-based analysis of arteriovenous malformation treatment. J Neurosurg 95:633-637, 2001

16. Hirai S, Mine S, Yamakami I, Ono J, Yamaura A: Angioarchi- tecture related to hemorrhage in cerebral arteriovenous malformations. Neurol Med Chir (Tokyo) 38 Suppl:165-170, 1998

17. Hofmeister C, Stapf C, Hartmann A, Sciacca RR, Mansmann $\mathrm{U}$, terBrugge $\mathrm{K}$, et al: Demographic, morphological, and clinical characteristics of 1289 patients with brain arteriovenous malformation. Stroke 31:1307-1310, 2000

18. Jessurun GA, Kamphuis DJ, van der Zande FH, Nossent JC: Cerebral arteriovenous malformations in the Netherlands Antilles. High prevalence of hereditary hemorrhagic telangiectasia-related single and multiple cerebral arteriovenous malformations. Clin Neurol Neurosurg 95:193-198, 1993

19. Joint Writing Group of the Technology Assessment Committee American Society of Interventional and Therapeutic Neuroradiology, Joint Section on Cerebrovascular Neurosurgery a Section of the American Association of Neurological Surgeons and Congress of Neurological Surgeons, Section of Stroke and the Section of Interventional Neurology of the American Academy of Neurology, Atkinson RP, Awad IA, Batjer HH, et al: Reporting terminology for brain arteriovenous malformation clinical and radiographic features for use in clinical trials. Stroke 32:1430-1442, 2001

20. Kim H, McCulloch CE, Johnston SC, Lawton MT, Sidney S, Young WL: Comparison of 2 approaches for determining the natural history risk of brain arteriovenous malformation rupture. Am J Epidemiol 171:1317-1322, 2010

21. Laakso A, Dashti R, Juvela S, Niemelä M, Hernesniemi J: Natural history of arteriovenous malformations: presentation, risk of hemorrhage and mortality, in Laakso A, Hernesniemi J, Yonekawa Y, et al (eds): Surgical Management of Cerebrovascular Disease. New York: Springer Wien, pp 65-70

22. Langer DJ, Lasner TM, Hurst RW, Flamm ES, Zager EL, King JT Jr: Hypertension, small size, and deep venous drainage are associated with risk of hemorrhagic presentation of cerebral arteriovenous malformations. Neurosurgery 42: 481-489, 1998

23. Mansmann U, Meisel J, Brock M, Rodesch G, Alvarez H, Lasjaunias P: Factors associated with intracranial hemorrhage in cases of cerebral arteriovenous malformation. Neurosurgery 46:272-281, 2000

24. Marks MP, Lane B, Steinberg GK, Chang PJ: Hemorrhage in intracerebral arteriovenous malformations: angiographic determinants. Radiology 176:807-813, 1990

25. Mast H, Young WL, Koennecke HC, Sciacca RR, Osipov A, Pile-Spellman J, et al: Risk of spontaneous haemorrhage after diagnosis of cerebral arteriovenous malformation. Lancet 350:1065-1068, 1997

26. McCormick WF: The pathology of vascular ("arteriovenous") malformations. J Neurosurg 24:807-816, 1966

27. Mine S, Hirai S, Ono J, Yamaura A: Risk factors for poor outcome of untreated arteriovenous malformation. J Clin Neurosci 7:503-506, 2000

28. Miyasaka Y, Yada K, Ohwada T, Kitahara T, Kurata A, Irikura $\mathrm{K}$ : An analysis of the venous drainage system as a factor in hemorrhage from arteriovenous malformations. J Neurosurg 76:239-243, 1992

29. Nataf F, Meder JF, Roux FX, Blustajn J, Merienne L, Merland JJ, et al: Angioarchitecture associated with haemorrhage in cerebral arteriovenous malformations: a prognostic statistical model. Neuroradiology 39:52-58, 1997

30. National Institute of Neurological Disorders and Stroke: A Randomized Trial of Unruptured Brain Arteriovenous Malformations (ARUBA). May 9, 2013 (http://www.ninds.nih. gov/news_and_events/news_articles/ARUBA_trial_results. htm) [Accessed July 16, 2014]

31. Nornes H, Grip A: Hemodynamic aspects of cerebral arteriovenous malformations. J Neurosurg 53:456-464, 1980

32. Ondra SL, Troupp H, George ED, Schwab K: The natural history of symptomatic arteriovenous malformations of the brain: 


\section{Natural history of BAVMs}

a 24-year follow-up assessment. J Neurosurg 73:387-391, 1990

33. Pollock BE, Flickinger JC, Lunsford LD, Bissonette DJ, Kondziolka D: Factors that predict the bleeding risk of cerebral arteriovenous malformations. Stroke 27:1-6, 1996

34. Stapf C, Mast H, Sciacca RR, Berenstein A, Nelson PK, Gobin YP, et al: The New York Islands AVM Study: design, study progress, and initial results. Stroke 34:e29-e33, 2003

35. Stapf C, Mast H, Sciacca RR, Choi JH, Khaw AV, Connolly ES, et al: Predictors of hemorrhage in patients with untreated brain arteriovenous malformation. Neurology 66:1350-1355, 2006

36. Stapf C, Mohr JP, Pile-Spellman J, Solomon RA, Sacco RL, Connolly ES Jr: Epidemiology and natural history of arteriovenous malformations. Neurosurg Focus 11(5):E1, 2001

37. Stefani MA, Porter PJ, terBrugge KG, Montanera W, Willinsky RA, Wallace MC: Large and deep brain arteriovenous malformations are associated with risk of future hemorrhage. Stroke 33:1220-1224, 2002

38. Turjman F, Massoud TF, Viñuela F, Sayre JW, Guglielmi G, Duckwiler G: Correlation of the angioarchitectural features of cerebral arteriovenous malformations with clinical presentation of hemorrhage. Neurosurgery 37:856-862, 1995
39. Viñuela F, Nombela L, Roach MR, Fox AJ, Pelz DM: Stenotic and occlusive disease of the venous drainage system of deep brain AVM's. J Neurosurg 63:180-184, 1985

40. Willinsky R, Lasjaunias P, Terbrugge K, Pruvost P: Brain arteriovenous malformations: analysis of the angio-architecture in relationship to hemorrhage (based on 152 patients explored and/or treated at the hospital de Biĉetre between 1981 and 1986). J Neuroradiol 15:225-237, 1988

41. Yamada S, Takagi Y, Nozaki K, Kikuta K, Hashimoto N: Risk factors for subsequent hemorrhage in patients with cerebral arteriovenous malformations. J Neurosurg 107:965-972, 2007

Manuscript submitted May 16, 2014.

Accepted June 10, 2014.

Please include this information when citing this paper: DOI: 10.3171/2014.6.FOCUS14250.

Address correspondence to: Bernard R. Bendok, M.D., M.S.C.I., Department of Neurological Surgery, Feinberg School of Medicine, Northwestern University, 676 N. St. Clair St., Ste. 2210, Chicago, IL 60611.email: bbendok@nmff.org. 